\title{
Fellowships
}

BESS is fully committed to education and, as part of this offers several fellowships to assist members in developing their knowledge and skills. The awards are made at the Annual Scientific meeting and are given on the basis of an interview by members of the Education Committee and past BESS Presidents.

Two Travelling Fellowships are available to one or more centres in the USA or Europe.

The Mayo award enables the recipient to attend the Mayo Clinic course and to stay for a short time afterwards.

The Allied Health Professional (AHP) award enables an AHP to travel to one or more centres to further their experience and knowledge.

The Continuous Professional Development (CPD) award is designed to enable a senior grade or junior consultant to attend a major conference or meeting.

This year two new Travelling Fellowships were created to honour the work and memory of Mr Stephen Copeland a past President of BESS. One AHP and one Consultant will be selected and will be required to act as ambassadors for BESS.

\section{The Dublin 2016 Fellowships}

The Dublin 2016 Fellowships were awarded to:

Travelling Fellowship 1: Harvinder Singh

Travelling Fellowship 2: Paul Cowling

Mayo Fellowship: Joideep Phadnis

AHP Fellowship: Jayanti Rai

CPD Fellowship: Niel Kang

Copeland Fellow (AHP): Valerie Jones

Copeland Fellow (Consultant): Chris Peach

Professor W Angus Wallace was granted Honorary Membership of BESS

\section{Prize winners}

During the BESS meeting, the Education Committee judge every paper and poster and award prizes according to strict criteria.

The Lipman Kessel prize is awarded to the presenter of the best paper read at the Annual Scientific Meeting.

The Ian Kelly prize is awarded to the presenter of the second highest scoring paper.

The Paul Calvert Endeavour prize is awarded to the presenter of the best paper from either a small institution or one with no established shoulder fellow.

The BESS AHP prize is awarded to the presenter of the best AHP read paper at the Annual Scientific Meeting. The BESS poster prize is awarded for the best poster at the Annual Scientific Meeting.

\section{The Dublin 2016 Prizes}

The Dublin 2016 Prizes were awarded to:

Lipman Kessel Prize. Reliability of glenoid track measurement for shoulder instability

A Schneider; G A Hoy; D Taylor; A Rotstein; E T H Ek; M Evans

Melbourne Orthopaedic Group, Melbourne Australia, Monash University, Melbourne, Australia 
lan Kelly Prize. An evidence and consensus based protocol for shoulder uss safely but significantly reduces the demand: a prospective study

R Gwyn; K Thomas; H Amos; I Gunatunga; C Connor; H Pullen; R Kulkarni

Royal Gwent Hospital, Newport, Gwent

Paul Calvert Endeavour Prize. An evidence and consensus based protocol for shoulder uss safely but significantly reduces the demand: a prospective study

R Gwyn; K Thomas; H Amos; I Gunatunga; C Connor; H Pullen; R Kulkarni

Royal Gwent Hospital, Newport, Gwent

AHP Prize. The use of videoconferencing (VC) consultations in the management of complex shoulder instability - A usability study

A Gilbert; C May; A Jaggi

Royal National Orthopaedic Hospital, Stanmore

BESS Poster Prize. Three-dimensional movement analysis of the upper limb, during activities of daily living, in children with obstetric brachial plexus palsy: a comparision with typically developing children

J Mahon; A Malone; D Kiernan; D Meldum

Central Remedial Clinic, Dublin and Royal College of Surgeons, Ireland 